\title{
Dietary Rhus coriaria L. powder reduces the blood cholesterol, VLDL-c and glucose, but increases abdominal fat in broilers
}

\author{
M. Golzadeh, P. Farhoomand ${ }^{\#}$ \& M. Daneshyar \\ Department of Animal Science, Faculty of Agriculture, University of Urmia, Urmia, Iran
}

Copyright resides with the authors in terms of the Creative Commons Attribution 2.5 South African Licence.

See: http://creativecommons.org/licenses/by/2.5/za

Condition of use: The user may copy, distribute, transmit and adapt the work, but must recognise the authors and the South African Journal of Animal Science.

\begin{abstract}
In an experiment, 200 one-day-old broiler chickens (Ross 308) were used to investigate the effects of sumac fruit (Rhus coriaria L.) powder (SFP) on performance, plasma concentrations of total cholesterol (TC), triglyceride (TG), high density lipoprotein (HDL-c), low density lipoprotein (LDL-c), very low density lipoprotein (VLDL-c) and plasma fasting blood sugar (FBS), as well as proportional abdominal fat. The chicks were divided into four treatment groups with 5 replicates and 10 birds in each. The birds were fed the basal diet (Z-SFP) or diets supplemented with 2.5 g SFP (L-SFP), 5 g SFP (M-SFP) and 10 g SFP (H-SFP) per kg diet. During the whole experimental period the H-SFP birds had a higher feed intake than the Z-SFP and L-SFP birds, though the H-SFP birds had higher feed conversion ratio compared with birds in the other treatments. No significant differences for body weight gain were recorded between the treatments. The MSFP and H-SFP birds had lower plasma TC and VLDL-c concentrations than the Z-SFP and L-SFP birds. No significant differences between the treatments were indicated for plasma TG, HDL-c and LDL-c concentrations. Moreover the plasma FBS concentration of the H-SFP birds was lower than the birds in treatments Z-SFP and L-SFP, but no significant differences were observed between the other treatments. Furthermore, significant negative correlations were found between SFP supplementation and plasma TC, VLDL-C and FBS concentrations and a significant positive correlation between SFP supplementation and abdominal fat weight. In conclusion, dietary supplementation of SFP reduces the blood TC, VLDL-c and FBS concentrations, which can be related to decreased activity of HMG-CoA reductase and $\alpha$-amylase activities. The higher abdominal fat weight of the SFP-fed birds is possibly related to changes of energy storage towards fat deposition.
\end{abstract}

Keywords: Fasting blood sugar, feed conversion ratio, feed intake, performance, sumac fruit

\#Corresponding author: p.farhoomand@urmia.ac.ir

\section{Introduction}

Heart disease is a cause of human deaths and is directly related to increased levels of plasma cholesterol. High total cholesterol (TC) and low high density lipoprotein cholesterol (HDL-c) concentrations are often associated with endothelium dysfunction and inflammation, which can be followed by atherosclerosis (Abdulkarimi et al., 2011). In addition, epidemiological and scientific evidence have shown a strong relationship between total fat intake and cellular cholesterol composition and a number of diseases, including coronary heart disease, cancer, diabetes, depression and Alzheimer's in humans (Okuyama et al., 1997; Henning \& Watkins, 1998; Leaf \& Kang, 1998; Katan, 2000; Ayerza et al., 2002; Michikawa, 2003). It is widely acknowledged that there is an urgent need for humans to return to a balanced fatty acid diet by decreasing their intake of cholesterol and saturated fats (Evans et al., 2002; Ponte et al., 2004). Therefore, lowering the dietary cholesterol level has become an important concern for people with heart diseases. Meat from the chicken is one of the main meat products consumed by humans. It is low in cholesterol and fat, and thus considered healthier than other meat products, especially red meat from mammalians. Although poultry meat has a lower fat and cholesterol content than other meat sources, several dietary treatments have been attempted to further decrease the concentration of these products in poultry meat (Wang, 2006). 
Nowadays, medicinal plants and their extracts or essential oils are the feed additives that are widely used in animal nutrition to improve fatty acid composition as well as the cholesterol contents of meat products. Dietary addition of additives such as turmeric (Daneshyar et al., 2012), oats (Lopez-Bote et al., 1998), garlic (Tapsell et al., 2006), thyme (Abdulkarimi et al., 2011), green tea (Wolfram et al., 2006; Lee et al., 2009) and alfalfa (Ponte et al., 2004) have been tested in animals. Sumac (Rhus coriaria L.) is a plant species in the anacardiaceae family that is used as a spice and a native medicine. Sumac is found in temperate and tropical regions worldwide, often growing in areas of marginal agricultural capacity. It has a long history of use by indigenous people for medicinal and other applications (Rayne \& Mazza, 2007; Capcarova et al., 2011). The fruits of sumac contain flavonols, phenolic acids, hydrolysable tannins, anthocyans and organic acids such as malice, citric and tartaric acids (Özcan \& Haciseferogullari, 2004; Gündüz et al., 2010). Sumac is used as an herbal remedy in traditional medicine because of its assumed analgesic, antidiarrhoetic, antiseptic, anorexic and antihypergylcaemic properties (Rayne \& Mazza, 2007; Chakraborty et al., 2009).

Sumac extracts have been found to have antimicrobial, hypoglycaemic and antioxidant activities (Rayne \& Mazza, 2007). Some studies have shown that polyphenols could have beneficial effects on cardiovascular disease (Hertog et al., 1995) and cancer (Noroozi et al., 1998), and could be regarded as bioactive compounds with a high potential health-promoting capacity. Phenolic compounds inhibit lipid peroxidation, scavenge the superoxide anion and hydroxyl radical (Ruby et al., 1995), and enhance the activities of detoxifying enzymes such as glutathione-S-transferase (Piper et al., 1998). Moreover, the hypocholesterolemic action of dietary polyphenols has been reported (Regerat, 1976; Tebib et al., 1994; Bravo, 1998). D-limonene (l-methyl-4-(1-methylethenyl)-cyclohexane) is a monocyclic monoterpene component of sumac that has hypocholesterolemic effects (Kurucu et al., 1993; Marshall, 1995; Victor Antony Santiago, 2010). The hypocholesterolemic effect of sumac fruit powder (SFP) and its components have been reported previously in rabbits and mice. Dietary supplementation of SFP up to $15 \mathrm{~g} / \mathrm{kg}$ for 90 days decreased TC in rabbits (Capcarova et al., 2011). In an experiment, consumption of $100 \mathrm{mg}$ glycoprotein/kg isolated from Rhus verniciflua stokes fruit (another sumac species) for two weeks caused decreased TC, triglyceride (TG) and low density lipoprotein (LDL-c) concentrations in mice (Oh et al., 2006). Although the plasma cholesterol lowering effects of SFP have been shown in rabbits and mice, no study is available on the effect of SFP on blood TC, TG, plasma fasting blood sugar (FBS) and other blood lipoproteins and even the performance of broiler chickens. Furthermore, abdominal fat accumulation was assessed as an indicator for meat quality. Fat accumulation in carcasses of broilers, particularly in abdominal and visceral areas, represents a waste product from the nutritional and health points of view to consumers. Such obese broilers are unpleasant to the consumers, lead to decreased saleability, and reduce net returns for the producers (Rabie \& Szilagyi, 1998; Abdulkarimi et al., 2011).

\section{Material and Methods}

In this experiment, 200 one-day-old male broiler chickens (Ross 308) were bought from a local hatchery, weighed on arrival and distributed among 20 pens $\left(1 \times 1 \mathrm{~m}^{2}, 10\right.$ birds in each pen). The temperature programme of the house has been reported elsewhere (Daneshyar et al., 2012). A lighting programme of $23 \mathrm{~h}$ light and $1 \mathrm{~h}$ darkness was used during the experiment. All the chickens were fed the same starter (from day 1 to day 21 of age) and grower (from day 22 to day 42 of age) diets in mash form (Table 1). During the experimental period $0.0 \mathrm{~g}$ SFP (Z-SFP), $2.5 \mathrm{~g}$ SFP (L-SFP), $5 \mathrm{~g}$ SFP (M-SFP) and $10 \mathrm{~g}$ SFP (H-SFP) $/ \mathrm{kg}$ diet were included in the basic diet. The experimental protocol was approved by the Ethical Committee of Urmia University for Animal Experiments.

Fresh sumac fruit was purchased, the impurities removed, and ground. The SFP (with total phenols of $34.8 \mathrm{mg} / \mathrm{g}$ ) was obtained from the local market and included in the diets in ground form. The FolinCiocalteau reagent and gallic acid (as the standard) were used to determine total phenols using a colorimetric method. One gram SFP was crushed in $10 \mathrm{~mL}$ of $80 \%$ methanol in a pestle and mortar. The extract was filtered and centrifuged at $5000 \mathrm{rpm}$ for $5 \mathrm{~min}$ and the supernatant was collected. Then, $0.5 \mathrm{~mL}$ of the extract was mixed with the Folin-Ciocalteau reagent $(1: 10 \mathrm{v} / \mathrm{v})$ and $\mathrm{Na}_{2} \mathrm{Co}_{3}(1 \mathrm{~mol})$. After $15 \mathrm{~min}$, this solution was used to determine total phenols using a spectrophotometer (single beam scanning UV/visible spectrophotometer, M 501, Unicosh Co., China) at absorbance of $765 \mathrm{~nm}$.

Body weight gain (BWG) and feed intake (FI) of the birds were measured during the whole experimental period and the feed conversion ratio (FCR, g feed/g gain) was calculated. At week 3, one 
chicken per replicate pen (five per treatment) was selected randomly for blood collection at weeks 3 and 6 . Blood from the wing vein was collected after three hours of starvation. Blood samples were immediately aliquoted into anticoagulant (EDTA) tubes. The plasma was separated by centrifuge at $3000 \mathrm{rpm}$ for $10 \mathrm{~min}$ and stored at $-20{ }^{\circ} \mathrm{C}$ for later analyses. At the end of the experiment (week 6), five chickens from each replicate (pen) were randomly selected and slaughtered. Plasma samples were thawed and their plasma TC, TG, LDL-c, HDL-c, very low density lipoprotein cholesterol (VLDL-c), and FBS were determined spectrophotometrically (spectrophotometer, Unico-2400, Japan) using a commercial enzymatic kit (Pars Azmon Co, Tehran, Iran).

Table 1 Composition of experimental diets

\begin{tabular}{lcc}
\hline & Starter $(1-21$ day) & Grower $(22-42$ day $)$ \\
\hline Ingredients (g/kg) & 498.7 & 556.3 \\
Maize & 411 & 357 \\
Soybean meal (44\% protein) & 37 & 41 \\
Soybean oil & 11.5 & 12.5 \\
Oyster shell & 21 & 14 \\
Dicalcium phosphate & 5 & 5 \\
Vitamin and mineral premix ${ }^{1}$ & 3.7 & 3.4 \\
Salt & 2.1 & 0.8 \\
DL-methionine & 10 & 10 \\
Sand & 1000 & 1000 \\
Total & & \\
Calculated analysis & 12.14 & 12.56 \\
Metabolizable energy (MJ/kg) & 220 & 200 \\
Crude protein (g/kg) & 8.8 & 8.9 \\
Calcium $(\mathrm{g} / \mathrm{kg})$ & 4.6 & 3.5 \\
Available phosphorus (g/kg) & 2.0 & 1.5 \\
Sodium (g/kg) & 15.2 & 12.7 \\
Arginine (g/kg) & 15.2 & 7.2 \\
Methionine + cystine (g/kg) & 12.3 & 11.0 \\
Lysine (g/kg) & 3.3 & 2.7 \\
Tryptophan $(\mathrm{g} / \mathrm{kg})$ & & \\
& &
\end{tabular}

\footnotetext{
${ }^{1}$ Vitamin premix per kg of diet: $2.7 \mathrm{mg}$ vitamin A (retinol); $0.05 \mathrm{mg}$ vitamin $\mathrm{D}_{3}$ (cholecalciferol); $18 \mathrm{mg}$ vitamin $\mathrm{E}$ (tocopheryl acetate); $2 \mathrm{mg}$ vitamin $\mathrm{K}_{3} ; 1.8 \mathrm{mg}$ thiamine; $6.6 \mathrm{mg}$ riboflavin; $10 \mathrm{mg}$ panthothenic acid; $3 \mathrm{mg}$ pyridoxine; $0.015 \mathrm{mg}$ cyanocobalamin; $30 \mathrm{mg}$ niacin; $0.1 \mathrm{mg}$ biotin; $1 \mathrm{mg}$ folic acid; $250 \mathrm{mg}$ choline chloride; $100 \mathrm{mg}$ antioxidant. Mineral premix per kg of diet: $50 \mathrm{mg} \mathrm{Fe}\left(\mathrm{FeSO}_{4} \cdot 7 \mathrm{H}_{2} \mathrm{O}, 20.1 \% \mathrm{Fe}\right) ; 100$ mg Mn ( $\left.\mathrm{MnSO}_{4} \cdot \mathrm{H}_{2} \mathrm{O}, 32.5 \% \mathrm{Mn}\right) ; 100 \mathrm{mg} \mathrm{Zn}(\mathrm{ZnO}, 80.4 \% \mathrm{Zn}) ; 10 \mathrm{mg} \mathrm{Cu}\left(\mathrm{CuSO}_{4} \cdot 5 \mathrm{H}_{2} \mathrm{O}\right) ; 1 \mathrm{mg} \mathrm{I}(\mathrm{KI}, 58 \%$ I); $0.2 \mathrm{mg}$ Se $\left(\mathrm{NaSeO}_{3}, 45.6 \% \mathrm{Se}\right)$.
}

The data were subjected to the analysis of variance procedure according to a completely randomized design using the general linear model procedure of SAS statistical software (SAS, 2002). Means were compared using Duncan's multiple test when treatment means were significant $(P<0.05)$. Correlation coefficients between SFP consumption and blood TC, VLDL-c, FBS concentrations and abdominal fat weight were calculated by the CORR procedure of SAS (SAS, 2002). 


\section{Results}

The dietary supplementation effects of SFP (1 to 42 days of age) on FI and FCR during the whole experimental period are shown in Figures 1 and 2, respectively. No significant differences were indicated between the treatments for BWG $(P>0.05)$, whereas the FI of H-SFP birds was significantly higher than that of the Z-SFP and L-SFP birds $(P<0.05)$ (Figure 1). Moreover, the FCR of H-SFP birds was higher than those of the other birds $(P<0.05)$ (Figure 2$)$.

There was no significant difference between the treatments for plasma TG, HDL-c and LDL-c concentrations. The plasma TC concentrations of the M-SFP and H-SFP birds were lower $(P<0.05)$ than that of the Z-SFP and L-SFP birds. Furthermore, the VLDL-c concentration of M-SFP and H-SFP birds was lower $(P<0.05)$ than that of Z-SFP and L-SFP birds. Although the plasma FBS of H-SFP birds was lower $(P$ $<0.05)$ than that of the Z-SFP and L-SFP ones, no significant differences were indicated between the M-SFP birds. Furthermore, the plasma FBS concentration of H-SFP-fed birds was higher than that of Z-SFP and S-SFP birds $(P<0.05)$ (Table 2$)$.

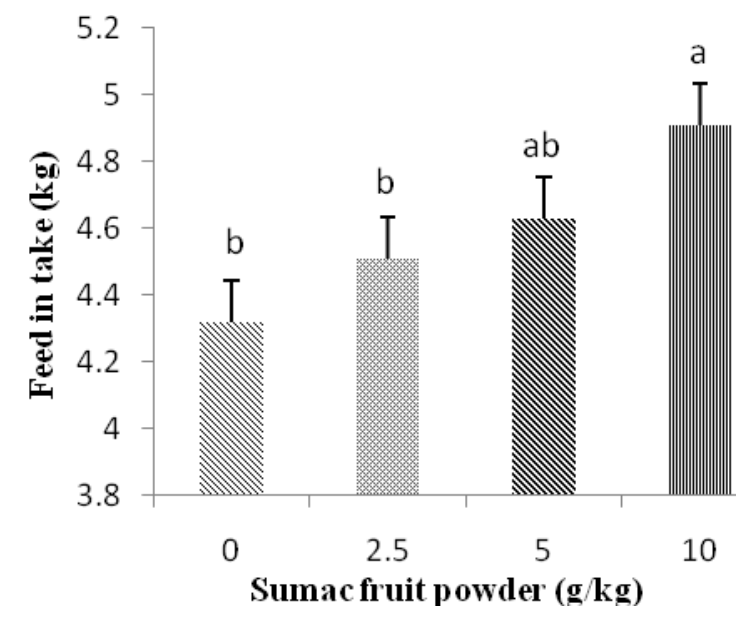

Figure 1 Effects of dietary supplementation of 0.0 (Z-SFP), 2.5 (L-SFP), 5 (M-SFP) and 10 (H-SFP) g sumac fruit powder/kg diet, on feed intake.

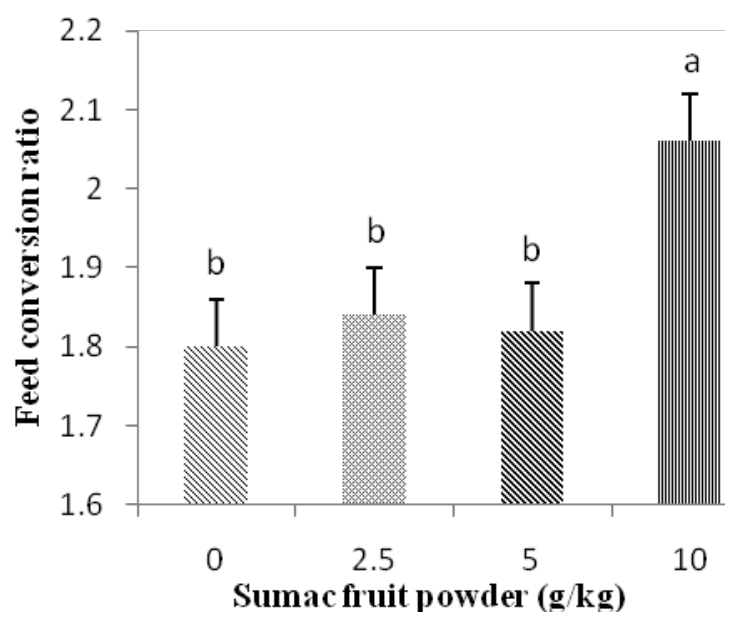

Figure 2 Effects of dietary supplementation of 0.0 (Z-SFP), 2.5 (L-SFP), 5 (M-SFP) and 10 (H-SFP) g sumac fruit powder/kg diet, on feed conversion ratio ( $\mathrm{g}$ feed/g gain).

Table 2 Blood indices of broiler chicken receiving 0 (Z-SFP), 2.5 (L-SFP), 5 (M-SFP) and $10 \mathrm{~g} / \mathrm{kg}$ (HSFP) sumac fruit powder supplemented diets

\begin{tabular}{lcccccc}
\hline Treatment & $\begin{array}{c}\text { TC } \\
\mathrm{mg} / \mathrm{dL}\end{array}$ & $\begin{array}{c}\text { TG } \\
\mathrm{mg} / \mathrm{dL}\end{array}$ & $\begin{array}{c}\text { LDL-c } \\
\mathrm{mg} / \mathrm{dL}\end{array}$ & $\begin{array}{c}\text { HDL-c } \\
\mathrm{mg} / \mathrm{dL}\end{array}$ & $\begin{array}{c}\text { VLDL-c } \\
\mathrm{mg} / \mathrm{dL}\end{array}$ & $\begin{array}{c}\text { F.B.S } \\
\mathrm{mg} / \mathrm{dL}\end{array}$ \\
\hline Z-SFP & $152.9^{\mathrm{a}}$ & 51.9 & 88.3 & 24.8 & $12.00^{\mathrm{ab}}$ & $233.8^{\mathrm{a}}$ \\
L-SFP & $151.5^{\mathrm{a}}$ & 55.5 & 108.1 & 30.3 & $14.7^{\mathrm{a}}$ & $229.5^{\mathrm{a}}$ \\
M-SFP & $107.5^{\mathrm{b}}$ & 51.3 & 86.6 & 24.0 & $8.9^{\mathrm{b}}$ & $221.3^{\mathrm{ab}}$ \\
H-SFP & $105.9^{\mathrm{b}}$ & 46.9 & 118.0 & 31.6 & $8.6^{\mathrm{b}}$ & $209.2^{\mathrm{b}}$ \\
SEM & 7.19 & 2.85 & 7.91 & 1.92 & 0.76 & 3.57 \\
$P$-value & 0.006 & 0.79 & 0.44 & 0.41 & 0.002 & 0.048
\end{tabular}

TC: total cholesterol; TG: triglyceride; LDL-c: low density lipoprotein; HDL-c: high density lipoprotein; VLDL-c: very low density lipoprotein; plasma F.B.S: fasting blood sugar.

Z-SFP: 0 g sumac fruit powder/kg; L-SFP: 2.5 g sumac fruit powder/kg; M-SFP: 5 g sumac fruit powder/kg; H-SFP: 10 g sumac fruit powder/kg diet.

${ }_{\mathrm{a}, \mathrm{b}}$ Means with no common superscript in columns differ significantly $(P<0.05)$; two birds per replicate $(8$ per treatment) were used for the determinations. 
In correlation analyses, significant negative correlations were found between SFP supplementation and plasma TC $(r=-0.63, P=0.003)$, VLDL-c $(r=-0.53, P=0.02)$ and FBS $(r=-0.63, P=0.004)$ concentrations, and a significant positive correlation between SFP supplementation and abdominal fat weight $(\mathrm{r}=0.53, P=0.02)$ (Table 3$)$.

Table 3 Pearson correlation coefficients between sumac fruit powder supplementation with plasma TC, TG, LDL-c, HDL-c, VLDL-c, FBS concentrations and proportional abdominal fat weight (\% of live body weight) of broiler chickens

\begin{tabular}{lcc}
\hline \multirow{2}{*}{ Blood indices } & \multicolumn{2}{c}{ Sumac fruit powder } \\
\cline { 2 - 3 } & $P$-value & R-value \\
\hline & 0.003 & -0.63 \\
TC (mg/dL) & 0.41 & -0.19 \\
LDL-c (mg/dL) & 0.28 & 0.25 \\
HDL-c (mg/dL) & 0.34 & 0.22 \\
VLDL-c (mg/dL) & 0.02 & -0.53 \\
FBS (mg/dL) & 0.004 & -0.63 \\
Proportional abdominal fat (\% of & 0.016 & 0.53 \\
live body weight) & & \\
\hline
\end{tabular}

\footnotetext{
${ }^{a}$ Results are presented as $P$ values of $\leq 0.05$ (significant) and $\mathrm{R}$ values for the significant correlations. One bird per replicate ( 5 per treatment) was used for the analyses.

TC: total cholesterol; TG: triglyceride; LDL-c: low density lipoprotein; HDL-c: high density lipoprotein;

VLDL-c: very low density lipoprotein; plasma FBS: fasting blood sugar.
}

\section{Discussion}

The results of the present study indicated that dietary supplementation of SFP, especially at high doses, worsens the performance of chickens. In this study, H-SFP-fed birds had the highest feed consumption and feed conversion ratio among the treatments. The deteriorated feed consumption and FCR of these birds may be related to the polyphenolic compounds of sumac. These negative effects of phenol compounds have been related to their influence on the availability of some nutrients. Sumac was reported as a rich source of tannin (Kosar et al., 2006). Polyphenols (Özcan \& Haciseferogullari, 2004; Gündüz et al., 2010) and gallic acid are the main polyphenolic constituents in sumac (Rayne \& Mazza, 2007). For example, Potter \& Fuller (1968) reported lower availability of methionine, choline and arginine in broiler chickens with the dietary supplementation of high tannic acid (1\%). Tannic acid apparently is hydrolysed to gallic acid, and a large part of this material is O-methylated and excreted in the urine as 4-O-methyl gallic acid. The source of methyl groups for the O-methylation of gallic acid is principally from choline and methionine (Potter \& Fuller, 1968). Moreover, tannins decrease the protein digestibility through their action on the brush border membrane of the small intestine, where enzymatic activity is mainly located (Marzo et al., 1990). The formation of an insoluble tannin-protein complex has been reported in the gastrointestinal tract by dietary supplementation of tannic acid (Tamir \& Alumot, 1970). Reports have also shown that tannic acid and degradation products are absorbed from the small intestine and caused toxic effects (Vohra et al., 1966; Kardivel et al., 1969; Karin et al., 1978; Marzo et al., 2002). Our results are in agreement with those of Marzo et al. (2002), who reported that dietary supplementation of tannic acid (15 g/kg feed) in broilers for 15 days resulted in increased feed consumption.

Our present study also indicated a negative correlation between the dietary SFP consumption and plasma total cholesterol and VLDL-c concentrations in broiler chickens, which is in agreement with findings of other researchers. The hypocholesterolemic action of sumac is possibly related to its polyphenolic components. Polyphenols have been shown to depress the reverse-cholesterol transport, reduce the intestinal cholesterol absorption, and even increase bile acid excretion (Regerat, 1976; Tebib et al., 1994; Bravo, 
1998). In agreement with our results, Capcarova et al. (2011) observed a declined plasma cholesterol concentration in male rabbits through the dietary supplementation of $15 \mathrm{~g}$ sumac fruit $/ \mathrm{kg}$. Similarly, Victor Antony Santiago et al. (2010) reported reduced serum cholesterol concentrations in rats consuming $2 \%$ d-limonene (a component of sumac essential oil) for four weeks. Dietary d-limonene inhibits the perillyl alcohol on 3-hydroxy-3-methylglutaryl HMG-CoA reductase activity, thus decreasing farnesyl pyrophosphate synthesis (Elson, 1995; Victor Antony Santiago et al., 2010) and the concentration of plasma cholesterol (Qureshi et al., 1988). Oh et al. (2006) obtained similar results in mice with a glycoprotein isolated from Rhus verniciflua fruit (another species of sumac). Another reason for the decreased plasma cholesterol by sumac is possibly related to its effect on 3-hydroxy-3-methylglutaryl CoA (HMG-CoA) reductase activity. Sumac contains essential oils, limonene $(0.17 \%-9.49 \%)$, nonanal $(10.77 \%-13.09 \%)$ and (Z)-2-decenal (9.90\% - 42.35\%) (Kurucu, 1993). Although the activity of HMG-CoA reductase was not investigated in the current experiment, Oh et al. (2006) related the cholesterol-lowering effect of glycoprotein isolated from Rhus verniciflua fruit to a higher activity of HMG-CoA reductase. Victor Antony Santiago et al. (2010) reported that lower blood cholesterol concentrations could be mediated by the stimulation of 3-hydroxy-3-methylglutaryl CoA reductase activity. A positive correlation has been reported between the activity of HMG-CoA reductase and TC or LDL-c in broiler chickens (Qureshi et al., 1983).

Furthermore, feeding of SFP to broiler chickens is negatively correlated with plasma FBS concentration. This reducing effect on plasma FBS could be related to a reduced activity of $\alpha$-amylase enzyme in SFP-fed birds. Giancarlo et al. (2006) observed hypoglycaemic activity of sumac fruit methanolic extract in vitro and reported the inhibition of $\alpha$-amylase activity ( $87 \%$ inhibition at $50 \mu \mathrm{g} / \mathrm{mL})$ as the reason. Another component of sumac, d-limonene, has resulted in lower blood FBS and insulin concentrations, and pancreatic b-cell mass in rat (Victor Antony Santiago et al., 2011).

In addition, dietary consumption of SFP positively changed the proportional abdominal fat weight in the body. In a similar study on broiler chickens, Pourreza \& Edris (1997) found a significant positive correlation between the amount of tannin consumption (from a sorghum source) and proportional abdominal fat weight in both male and female chickens. These scientists reported possible negative effects of tannins in sorghum on protein digestibility and reduction of amino acids availability and protein synthesis as the consequence. This phenomenon leads to direct storage of energy as fat (Pourreza \& Edris, 1997) and hence increased proportional abdominal fat weight. Similarly to sorghum, tannins from sumac possibly increase the energy storage as fat, which results in higher proportional abdominal fat.

\section{Conclusion}

According to our results, dietary supplementation of SFP reduces the blood TC and VLDL-C concentrations, which can be related to stimulated activity of the HMG-CoA reductase enzyme. Declined plasma FBS concentration of sumac-fed birds is related to lower $\alpha$-amylase activity. Furthermore, dietary SFP consumption resulted in higher abdominal fat weight that is possibly connected to lower availability of amino acids and protein that changes the energy storage towards the fat. Furthermore, dietary SFP supplementation, especially in high doses, worsens the performance of broiler chickens. The reduced feed consumption and FCR of these birds may be related to the high polyphenols contents of sumac.

\section{References}

Abdulkarimi, R., Daneshyar M. \& Aghazadeh, A., 2011. Thyme (Thymus vulgaris) extract consumption darkens liver, lowers blood cholesterol, proportional liver and abdominal fat weights in broiler chickens. Ital. J. Anim. Sci. 10, 101-105.

AOAC, 1998. Official Methods of Analysis of the Association of Official Analytical Chemists. (15th ed.). Association of Official Analytical Chemists, Washington, D.C., USA.

Ayerza, R., Coates, W. \& Lauria, M., 2002. Chia seed (Salvia hispanica L.) as an $\omega-3$ fatty acid source for broilers: Influence on fatty acid composition, cholesterol and fat content of white and dark meats, growth performance and sensory characteristics. Poult. Sci. 81, 826-837.

Bravo, L., 1998. Polyphenols: chemistry, dietary sources, metabolism, and nutritional significance. Nutr. Rev. 31, 7-333.

Capcarova, M., Slamecka J., Abbas, K., Kolesárová, A., Kalafova, A., Valent, M., Filipejova, T., Chrastinova, L., Ondruska, L. \& Massanyi, P., 2011. Effects of dietary inclusion of Rhus coriaria on internal milieu of rabbits. J. Anim. Physiol. Anim. Nutr. 96, 459-465. 
Chakrabortya, A., Ferka, F., Simić, T., Brantnerb, A., Dusinšká, M., Kundid, M., Christine, H., Nersesyan, A. \& Knasmuller, S., 2009. DNA-protective effects of sumach (Rhus coriaria L.), a common spice: results of human and animal studies. Mutat. Res. 661, 10-17.

Crowell, P.L. \& Gould, M.N., 1994. Chemoprevention and therapy of cancer by d-limonene. Crit. Rev. Oncog. 5, 1-22.

Daneshyar, M., Alizadehm Ghandkanlo, M., Sabzi Bayeghra, F., Farhangpajhoh, F. \& Aghaei, M., 2011. Effects of dietary turmeric supplementation on plasma lipoproteins, meat quality and fatty acids composition in broilers. S. Afr. J. Anim. Sci., 41, 420-428.

Elson, C.E., 1995. Suppression of mevalonate pathway activities by dietary isoprenoids: protective roles in cancer and cardiovascular disease. J. Nutr. 125, 1666S-1672S.

Evans, M., Roberts, A. \& Rees, A., 2002. The future direction of cholesterol-lowering therapy. Curr. Opin. Lipidol. 13, 663-669.

Giancarlo, S., Rosa, L.M., Nadjafi, F. \& Francesco, M., 2006. Hypoglycaemic activity of two spices extracts: Rhus coriaria L. and Bunium persicum Boiss. Nat. Prod. Res. 20, 882-886.

Gönül, A. \& Karapinar, M., 2010. Efficacy of sumac and oregano in the inactivation of Salmonella typhimurium on tomatoes. Int. J. Food. Microbiol. 141, 39-44.

Henning, B. \& Watkins, B. A., 1998. Dietary lipid guidelines for infants and children: considerations for growth and disease risk: In: Lipids in Infant Nutrition. AOCS press. pp. 235-251.

Hertog, M.G.L., Kromhout, D., Aravanis, C., Blackburn, H., Buzina, R., Fidanza, F., Giampaoli, S., Jansen, A., Menotti, A., Nedeljkovc, S., Pekkarinen, M., Simic, B.S., Toshima, H., Feskens, E.J.M., Hollman P.C.H. \& Katan, M.B., 1995. Flavonoid intake and long-term risk of coronary heart disease and cancer in the Seven Countries Study. Arch. Int. Med. 155, 381-386.

Kadirvel, R., Rayudu, G.V.N. \& Vohra, P., 1969. Toxicity of tannic acid and its metabolites for chickens. Poult. Sci. 48, 1511-1513.

Karin, S.A., Pand, N.C., Sahu, B.K. \& Nayak, B.C., 1978. A note on histopathological studies on the organs of chicks fed tannic acid in the diets. Indian J. Anim. Sci. 48, 326-330.

Katan, M., Zock, P. \& Mensink, R., 1995. Dietary oils, serum lipoproteins, and coronary heart disease. Am. J. Clin. Nutr. 61, 1368-1373.

Kosar, M., Bozan, B., Temelli, F. \& Baser, K.H.C., 2006. Antioxidant activity and phenolic composition of sumac (Rhus coriaria L.) extracts. Food. Chem.103, 952-959.

Kurucu, S., Koyuncu, M., Guvenc, A., Baser, K.H.C. \& Ozek, T., 1993. The essential oil of Rhus coriaria L. (sumac). J. Essent. Oil Res: Jeor. 5, 481-486.

Leaf, A. \& Weber, P.C., 1987. A new era for science in nutrition. Am. J. Clin. Nutr. 45, 1048-1053.

Lee, M.S., Kim, C.T. \& Kim, Y., 2009. Green tea epigallocatechin-3-gallate reduces body weight with regulation of multiple genes expression in adipose tissue of diet-induced obese mice. Ann. Nutr. Metabol. 54, 151-157.

Lopez-Bote, C.J., Grar, J.I., Gomaa, E.A. \& Flegal, C.J., 1998. Effect of dietary oat administration on lipid stability in broiler meat. Br. Poult. Sci. 39, 57-61.

Marshall, J.R., 1995. Editorial: improving American's diet-setting public policy with limited knowledge. Am. J. Public. Health 85, 1609-1611.

Marzo, F., Tosar, A. \& Santidrian, S., 1990. Effect of tannic acid on the immune response of growing chickens. J. Anim. Sci. 40, 1189-1197.

Marzo, F., Urdaneta, E. \& Santidrian, S., 2002. Liver proteolytic activity in tannic acid-fed birds. Poult. Sci. 81, 92-94.

Michikawa, M., 2003. The role of cholesterol in pathogenesis of Alzheimer's disease: Dual metabolic interaction between amyloid beta-protein and cholesterol. Mol. Neurobiol. 27, 1-12.

Noroozi. M., Angerson, W.J. \& Lean, M.E.J., 1998. Effects of flavonoids and vitamin C on oxidative DNA damage to human lymphocytes. Am. J. Clin. Nutr. 67, 1210-1218.

Oh, P.S., Lee, S.J. \& Lim, K.T., 2006. Hypolipidemic and antioxidative effects of the plant glycoprotein (36 $\mathrm{kDa}$ ) from Rhus verniciflua stokes fruit in Triton WR-1339- induced hyperlipidemic mice. Biosci. Biotech. Bioch. 70, 447-456.

Okuyama, H., Kobayashi, T. \& Watanabe, S., 1997. Dietary fatty acids the n-6/n-3 balance and chronic elderly diseases, excess linoleic acid and relative n-3 deficiency syndrome seen in Japan. Prog. Lipid. Res. 35, 409-457. 
Özcan, M. \& Haciseferogullari, H., 2004. A condiment sumac (Rhus coriaria L.) fruits: Properties. Bulg. J. Plant. Physiol. 30, 74-84.

Piper, J.T., Singhal, S.S., Salameh, M.S., Torman, R.T., Awasthi, Y.C. \& Awasthi, S., 1998. Mechanisms of anticarcinogenic properties of curcumin. the effect of curcumin on glutathione linked detoxification enzymes in rat liver. Int. J. Biochem. Cell. Boil. 30, 445-456.

Ponte, P.I., Mendes, I., Quaresma, M., Aquia, M.N., Lemos, J.P., Ferreira, L.M., Soares, M.A., Alfaia, C.M., Prates, J.A. \& Fontes, C.M., 2004. Cholesterol levels and sensory characteristics of meat from broilers consuming moderate to high levels of alfalfa. Poult. Sci. 83, 810-814.

Potter, D.K. \& Fuller, H.L., 1968. Metabolic fate of dietary tannins in chickens. J. Nutr. 96, 187-191.

Pourreza, J.M. \& Edris, A., 1997. Effects of dietary sorghum of different tannin concentrations and tallow supplementation on the performance of broiler chicks. Br. Poult. Sci. 38, 512-517.

Qureshi, A.A., Din, Z.Z., Abuirmeileh, N., Burger, W.C., Ahmad, Y. \& Elson, C.E., 1983. Suppression of avian hepatic lipid metabolism by solvent extracts of garlic: Impact on serum lipids. J. Nutr. 113, 1746-1755.

Rabie, M.H. \& Szilagyi, M., 1998. Effects of L-carnitine supplementation of diets differing in energy levels on performance, abdominal fat content, and yield and composition of edible meat of broilers. Br. J. Nutr. 80, 391-400.

Rayne, S. \& Mazza, G., 2007. Biological activities of extracts from sumac (Rhus spp.): a review. Plant. Food. Hum. Nutr. 62, 165-175.

Régérat, F., Rémésy, C., Tixier, O., Demigné, C. \& Levrat, A.M., 1992. Effects of condensed tannins and pectin on cecal fermentations and lipid metabolism in the rat. Bull. Liaison. Groupe. Polyphenols 16, 201-204.

Ruby, A.J., Kuttan, G., Babu, K.D., Rajasekharan, K.N. \& Kuttan, R., 1995. Antitumor and antioxidant activity of natural curcuminoids. Cancer Lett. 94, 79-83.

SAS, 2002. Statistical Analysis System users guide: (version 9.1). SAS Institute, Inc., Cary, N.C., USA

Tamir, M. \& Alumot, E., 1970. Carob tannins-growth depression and levels of insolubile nitrogen in the digestive tract of rats. J. Nutr. 100, 573-580.

Tapsell, L.C., Hemphill, I., Cobiac, L., Patch, C.S., Sullivan, D.R., Fenech, M., Roodenrys, S., Keogh, J.B., Clifton, P.M., Williams, P.G., Fazio, V.A. \& Inge, K.E., 2006. Health benefits of herbs and spices: the past, the present, the future. Med. J. Aust. 185, S4-24.

Tebib K., Bitri, L., Besanqon, P. \& Rouanet, J.M., 1994. Polymeric grape seed tannins prevent plasma cholesterol changes in high-cholesterol-fed rats. Food Chem. 49, 403-406.

Victor Antony Santiago, J., Jayachitra, J., Shenbagam, M. \& Nalini, N., 2010. d-limonene attenuates blood pressure and improves the lipid and antioxidant status in high fat diet and L-NAME treated rats. J. Pharm. Sci. 11, 752-758.

Victor Antony Santiago, J., Jayachitra, J., Shenbagam, M. \& Nalini, N., 2011. Dietary d-limonene alleviates insulin resistance and oxidative stress-induced liver injury in high-fat diet and L-NAME-treated rats. Eur. J. Nutr. 51, 57-68.

Vohra, P., Kratzer, F.H. \& Joslyn, M.A., 1966. The growth depressing and toxic effects of tannins to chicks. Poult. Sci. 45, 135-142.

Wang, J.J., Pan, T.M., Shieh, M.J. \& Hsu, C.C., 2006. Effect of red mold rice supplements on serum and meat cholesterol levels of broilers chicken. Appl. Microbiol. Biot. 71, 812-818. 